\title{
Analysis on Spatial Aggregation and Heterogeneity of Carbon Dioxide Emissions
}

\author{
Hao Guo, Dong Wang, Zhijun Liang* and Chunyu Song \\ School of Economics and Management, Harbin Institute of Technology, Shenzhen, 518055 Guangdong, China
}

Received 9 December 2018; Accepted 22 May 2019

\begin{abstract}
Carbon dioxide emissions within regions affect one another in space, and factors that influence carbon dioxide emissions show different spatial characteristics. To show the spatial aggregation of carbon dioxide emissions and the heterogeneity of the influencing factors, the spatial aggregation analysis model and spatial heterogeneity analysis model were constructed in this study. The Global Moran-Index (Moran'sI) was used to construct the spatial aggregation analysis model of carbon dioxide emissions, and the spatial geographic weighted regression analysis was used to construct the heterogeneous model of the influencing factors. The aggregation and heterogeneity were analyzed, and the validity of the model results was verified by unbiased estimation test and significance analysis. Results demonstrate that, the Moran'sI value of carbon dioxide emissions is greater than 0.6 , and carbon dioxide emissions indicate strong spatial correlation and clear spatial agglomeration characteristics; By using the weighted regression of spatial geography, it is also found that the spatial affect of influencing factors on carbon dioxide emissions presents different distribution characteristics, thereby confirming the existence of spatial heterogeneity. The study provides references for the implementation of regional energy conservation and carbon emission reduction policies.
\end{abstract}

Keywords: Spatial aggregation, Heterogeneity, Carbon dioxide emissions

\section{Introduction}

The acceleration of energy consumption causes a series of problems, such as the reduced carrying capacity of resources and the environment, and the exhausted natural resources. Many countries and regions are starting to focus on the growth of large-scale greenhouse gas emissions. Global climate change is mainly caused by large-scale greenhouse gas emissions, and its excessive emissions worsen the daily environmental quality and also seriously affect the living, social, and even cultural environment of humans[1-2]. At present, all aspects of carbon dioxide emissions, from industrial production and national economic development to the lives of living creatures cannot be separated from the consumption of fossil fuels. Carbon dioxide is the main emissions of fossil fuels. Therefore, the reduction of carbon dioxide emissions is attracting considerable attention from researchers worldwide.

Human beings are beginning to focus on the issue of climate change because of increasing awareness on the consequential problems caused by climate warming. As a responsible country, China is committed to making its own contribution by targeting to reach the peak of carbon emissions by 2030 [3-4]. Guangdong, with its large energy consumption, is one of the pilot areas attempting to become a province in China with low-carbon emissions. Hence, this province must actively and urgently explore methods and measures for carbon emissions reduction. Research on the role of spatial aggregation and heterogeneity of carbon emission in Guangdong Province is conducive to providing

\footnotetext{
*E-mail address: LiangZJ924@163.com

ISSN: 1791-2377 @ 2019 Eastern Macedonia and Thrace Institute of Technology. All rights reserved. doi:10.25103/jestr.122.23
}

effective suggestions.

Considerable studies on the mechanism of carbon dioxide emissions reduction are conducted from the perspective of energy consumption [5-8]. However, the majority of these studies only involves an ordinary panel of econometric models at the macro level, thereby deviating from the requirement of practical countermeasures on carbon emissions reduction. Therefore, selecting the suitable econometric model for this study based on the role of carbon dioxide emissions, determining the relationships between carbon dioxide emissions and the influencing factors, and presenting effective countermeasures on carbon dioxide emission reduction are necessary.

Hence, this study reviews the findings on carbon dioxide emissions in many fields, and finds that many studies are conducted from the macro perspective of the country. Only a few scholars analyze the micro situation within the province. Therefore, under the condition that the economy of Guangdong is improving gradually, the entrepreneurial atmosphere is prevailing and the achievements in scientific and technological innovation are outstanding, then study on the influence of carbon dioxide emissions in this province can provide a reference for implementation and promotion. The use of spatial econometric and weighted regression models in spatial geography analyzes the spatial characteristics of regional carbon dioxide emissions and the action mechanism of related factors. Moreover, the extent of the effect of these factors on the spatial heterogeneity of carbon dioxide emissions is analyzed to provide a reference for the preparation of effective policies on energy conservation and emission reduction. 


\section{State of the art}

In terms of the evolution of measurement and calculation methods in energy consumption and carbon dioxide emissions, Hulten (1973) first studied energy consumption through factor decomposition method, and improved and modified the decomposition method, but did not analyze how to effectively reduce energy consumption and thereby reduce carbon dioxide emissions [9]; In order to be able to better understand the influence of the relationship between manufacturing industry aggregation in industrial structure change and energy consumption in Korean, based on Mean Divisia Index(MDI) in the study for the application of energy intensity decomposition method, Boyd (1987) proposed Arithmetic Mean Divisia Index Method(AMDI), and the study analyzed calculated energy consumption mainly from the industrial structure and industrial aggregation, with no in-depth analysis to the relationship between energy consumption and emissions reduction of carbon dioxide [10]; Subsequently, Ang and Liu (2000) proposed the Logarithmic Mean Divisia Index (LMDI) decomposition method, which made some improvement based on AMDI [11]; following this, more measurement and calculation models based on different models were also proposed, for example, the input-output method and Stochastic Regression on Population, Affluence and Technology (STIRPAT)were used to measure and calculate the relationship between energy consumption and carbon dioxide emissions; even though these studies made certain innovation in measurement and calculation methods, they were short of studies on how to effectively reduce carbon dioxide emissions, and most researchers studied how to accurately measure and calculate energy consumption or carbon dioxide emissions in different research perspectives or methods, but did not conduct in-depth studies on energy conservation or emission reduction.

As for the method on reduction of regional carbon emissions, Emmanouil and Heracles et al. (2008) broke down the change of carbon dioxide emissions into four factors, income effect, energy intensity effect, fuel sharing effect and population effect, by using factor decomposition method for Greece from 1990 to 2002, and analyzed the influence of four different effects on carbon dioxide emissions, so as to put forward the countermeasures for carbon emission reduction, but, the analysis were only based on the macro level of the country, without analysis results at further micro level [12]. Mei linhai, Yang Hui (2011) and Chen Lin (2013) adopted They used gray relational analysis and industrial relational analysis to analyze carbon emission reduction, and found that the relational degree between coal energy consumption and carbon emissions was the highest, and that the change of production technology and direct carbon emissions intensity played a great role in China's carbon emission intensity. They made the conclusion that production technology was conducive to reducing carbon dioxide emissions, but they ignored the effect of spatial correlation between regions on influencing factors, and did not further explore the role of spatial factors correlation from a spatial perspective [13-14]. At the same time, many Chinese scholars have analyzed the issue of carbon emission reduction in China. For example, Li Guozhi and Li Zongzhi (2010) used STIRPAT model to make an empirical analysis of carbon emissions, discussed the influencing factors of regional carbon emissions in 30 provinces of China, and concluded that there were obvious differences in carbon emissions and the role of their influencing factors in different regions, and then concluded that different regions should prepare different carbon emission reduction strategy, but the conclusions drawn from the regional analysis at provincial level were still difficult to act as practical reference in terms of policy promotion [15]. Li Yuan et al. (2012) also adopted STIRPAT model for empirical analysis of carbon emissions, and through the empirical analysis of carbon dioxide emissions of in different China's industrial sectors, they found that different industrial sectors had different impacts on carbon dioxide emissions, but the influencing factors considered were relatively few [16]. Some scholars also tried to study carbon dioxide emission reduction from a micro regional perspective. For example, Zhao Xin and Long Ruyin (2010), Wang Peng and Zhang Renhui (2014), Shen Ziqi and Tang Decai (2014) adopted LMDI decomposition method, and found that regional economic development, expansion of construction land could increase carbon dioxide emissions, and that scientific and technological progress and optimization of energy structure could reduce carbon dioxide emissions, and that industrial restructuring had no obvious effect on carbon dioxide emission reduction; but spatial heterogeneity and spatial correlation of influencing factors were not considered [17-19]

Also, Heil and Wodo (1997) used the Gini coefficient method to decompose the data between 1960 and 1990 and found that the use of fossil fuels and the level of inequality between rich and poor countries had influence with different degrees on carbon emissions, but the research was at macro level and was not suitable for promotion [20]; Padilla and Serrano (2006) also used the Gini coefficient method in study and found that the unequal development of different countries was an important factor that leads to the uneven distribution of carbon emissions, but the analysis was from perspective of relatively macro level and was not enough for promotion [21]; Duro and Padilla (2006), by using the Thiel Index, found that income gap was the main reason for the difference in carbon dioxide emissions between countries and that the relationship curve between income level and carbon emissions was like an inverted "U", but no corresponding research had been conducted on how to reduce emissions [22]; Cantore and Padilla (2010) analyzed the equal distribution of carbon emissions through the coefficient of variation and other methods, and the research lacked the spatial perspective to study carbon emission reduction [23]; Clarke-Sather et al. (2011) synthesized the coefficient of variation, Gini coefficient and Theil Index, and concluded that there was imbalance of carbon dioxide emissions between different provinces in China and that there were differences between regions, but the research did not explore the conclusion or research countermeasures to reduce carbon emissions from the perspective of spatial correlation [24]; Zhang (2011) developed a model to decompose carbon emissions into four dimensional factors to discuss the potential strategies for China's carbon emission reduction respectively, but the research had no carbon emission reduction strategies at the provincial and municipal level [25]; Meng (2011) used panel data to analyze the characteristics of China's regional carbon dioxide emissions from 1997 to 2009, and concluded that the regional elasticity of per capita Gross Domestic Product (GDP) and energy intensity on carbon emissions also reflected the differences in regional economic development and economic structure, but the influence of regional carbon emission reduction was not considered in depth from the 
perspective of inter-regional correlation [26]; Lin Boqiang and Huang Guangxiao (2011) used spatial econometric model to analyze the distribution of carbon emissions among regions in China, and concluded that the carbon emissions from the West to the East feature a downward trend, but the per capita carbon emissions were the opposite, but the factors considered were relatively few [27]; Yang Qian and Liu Huajun (2012) used the Theil Index to study the carbon emissions in the three regions of China: East, West and Middle, and drew a conclusion that the difference of carbon emission intensity was greater than that of per capita carbon emissions, but the research was conducted only at the provincial data level, and had no analysis conclusion from the regional perspective of prefecture-level cities [28]; Xiao and $\mathrm{Hu}$ et al. (2015) found that regional differences and changes in energy efficiency of regional logistics have certain convergence, but the research was not conducted in depth on how to reduce carbon dioxide emissions [29].

These existing studies are mainly through analyzing the mechanism of carbon dioxide emissions from the national or provincial panel data model, while there is less literature studying the mechanism of carbon dioxide emissions from the perspective of cities. In particular, there are almost no studies on the effects of carbon dioxide emissions through spatial econometric models and the weighted regression models of spatial geography. In view of this, the selection of suitable research objects becomes the key to this study, in order to further study the influencing factors of carbon dioxide emissions reduction at the city level, and at the same time to consider the regional spatial correlation. Therefore, this study selects 21 prefecture-level cities as research objects in Guangdong province, a China's low-carbon pilot province. Based on the data of Guangdong prefecture-level cities from 2006 to 2015, a spatial econometric model and a regression model of spatial geography are built. Through the action mechanism between economic growth and carbon dioxide emissions, the study analyzes the spatial heterogeneity of influencing factors and the spatial aggregation degree of carbon dioxide emissions, providing important reference for China's carbon emission reduction.

The remainder of this study is organized as follows. Section 3 establishes the measurement method of carbon dioxide and the definition of the influencing factors, and constructs the model for the effect of carbon dioxide. Section 4 discusses the spatial aggregation and heterogeneity of influencing factors through spatial econometric model and geographically weighted regression model, and specifies the effect of different influencing factors. Section 5 summarizes the conclusions.

\section{Methodology}

\subsection{Variable Definition}

The proposed PSO-based network-clustering algorithm works as follows: This section provides a concise and precise description of the experimental results, their interpretation as well as the experimental conclusions that can be drawn. For the measurement method of carbon emissions from energy consumption, this study mainly refers to the method used by Song Deyong (2011)[31]. The spatial sample data of this study mainly come from the Statistical Yearbook of Guangdong province from 2006 to 2015, and some of them come from the Statistical Yearbook of 21 prefecture-level cities in Guangdong province. The time span is 10 years. Based on the Kaya theory and the research foundation of the influencing factors of carbon emissions by Li Jianbao (2015) and others, and considering the obvious influence of transportation on carbon emissions, the study mainly analyses the driving factors of carbon emissions from the aspects of population, economy, investment, consumption and transportation. The selected indicator of carbon emissions from energy consumption is the explained variable, namely per capita carbon emissions (ACO2) from energy consumption, while the explaining variables are per capita gross national product (agdp), industrial structure (stru, the proportion of secondary industry), permanent residents at the end of the year (popu), energy consumption intensity (ener), per capita gross investment in fixed assets (afix), per capita gross retail sales of consumer goods (aconsu) and per capita private car ownership (acar). The summary of variable definitions is shown in Table 1 .

\subsection{Model Building Process}

According to the selected indicators, the following panel model is constructed:

$$
\boldsymbol{A C O}_{2 i j}=\boldsymbol{f}\left(\begin{array}{l}
\operatorname{stru}_{i j}, \operatorname{agdp}_{i j}, \operatorname{popu}_{i j}, \text { ener }_{i j}, \\
\operatorname{afix}_{i j}, \operatorname{aconsu}_{i j}, \operatorname{acar}_{i j}
\end{array}\right)+u_{i j}
$$

In the formula,

$$
\begin{aligned}
& \mathrm{ACO}_{2} \longrightarrow \text { Per capita carbon emissions; } \\
& \text { stru-Industrial structure; } \\
& \boldsymbol{a g d p} \text { _Per capita gross national product; } \\
& \text { popu___ Permanent residents at the end of the year; } \\
& \text { ener —Energy consumption intensity; } \\
& \text { afix_-Per capita gross investment in fixed assets; } \\
& \text { aconsu-Per capita gross retail sales of consumer }
\end{aligned}
$$
goods;

acar__ Per capita private car ownership;

$\boldsymbol{u}$ - Random error ;

$i-$ Serial number of the cities $(i=1,2, \ldots, 21)$;

$\boldsymbol{j}$ - The year $(j=2006,2007, \ldots, 2015)$

In order to eliminate the difference in order of magnitude and possible heteroscedasticity of variables, we can make logarithmic changes to some indicators.

$$
\begin{aligned}
& \operatorname{lnC}_{i j}=\beta_{0}+\beta_{l} \operatorname{lnstru}_{i j}+\beta_{2} \operatorname{lnagd}_{i j}+\beta_{3} \operatorname{lnpopu}_{i j}+ \\
& \beta_{4} \operatorname{lnener}_{i j}+\beta_{5} \operatorname{lnafix}_{i j}+\beta_{6} \operatorname{lnacons}_{i j}+\beta_{7} \operatorname{lnacar}_{i j}+u_{i j}
\end{aligned}
$$

In the formula,

$\beta_{1}-$ Coefficient of industrial structure's impact on regional carbon emissions;

$\beta_{2}-$ Coefficient of economic growth impact on regional carbon emissions;

$\beta_{3} \longrightarrow$ Coefficient of population size impact on regional carbon emissions;

$\beta_{4} \longrightarrow$ Coefficients of energy intensity impact on regional carbon emissions;

$\beta_{5} \longrightarrow$ Coefficient of per capita fixed assets investment impact on regional carbon emissions;

$\beta_{6}-$ Coefficient of gross retail sales of consumer goods impact on regional carbon emissions; 
$\beta_{7} \longrightarrow$ Coefficient of per capita private car ownership impact on regional carbon emissions

Table 1. Summary of Variable Definitions

\begin{tabular}{|c|c|c|c|}
\hline Variable Name & Symbol & Unit & Variable Specification \\
\hline Per capita carbon emissions & $\mathrm{ACO}_{2}$ & Ton equivalent & $\begin{array}{l}\text { Ratio of carbon emissions from urban total energy consumption to } \\
\text { permanent residents at the end of the year }\end{array}$ \\
\hline Per capita gross national product & $\operatorname{agdp}$ & Ten thousand yuan & Per capita gross national product excluding inflation based on 2000 \\
\hline Industrial structure & stru & $\%$ & $\begin{array}{c}\text { Ratio of urban secondary industry added value to urban gross national } \\
\text { product excluding inflation based on } 2000\end{array}$ \\
\hline $\begin{array}{l}\text { Permanent residents at the end of } \\
\text { the year }\end{array}$ & рори & Ten thousand people & Value of permanent residents at the end of the year \\
\hline Energy consumption intensity & ener & $\%$ & $\begin{array}{c}\text { Ratio of energy consumption to urban gross national product excluding } \\
\text { inflation based on } 2000\end{array}$ \\
\hline $\begin{array}{l}\text { Per capita gross investment in } \\
\text { fixed assets }\end{array}$ & afix & Yuan & $\begin{array}{l}\text { Ratio of urban gross investment in fixed assets to urban permanent } \\
\text { residents at the end of the year excluding inflation based on } 2000\end{array}$ \\
\hline $\begin{array}{l}\text { Per capita gross retail sales of } \\
\text { consumer goods }\end{array}$ & aconsu & Yuan & $\begin{array}{c}\text { Ratio of urban gross retail sales of consumer goods to urban permanent } \\
\text { residents at the end of the year }\end{array}$ \\
\hline Per capita private car ownership & acar & $\begin{array}{l}\text { Vehicles / ten thousand } \\
\text { people }\end{array}$ & $\begin{array}{l}\text { Ratio of urban private car ownership to urban permanent residents at } \\
\text { the end of the year }\end{array}$ \\
\hline
\end{tabular}

* Data Sources: Statistical Yearbook of Guangdong province

\subsection{Analysis Steps of Spatial Correlation}

The spatial autocorrelation is usually measured by the Moran'sI, which was proposed by Moran (1950) to test the autocorrelation of spatial econometric model [32], which was defined by the following formula (3) :

$$
\text { Moran'sI }=\frac{\sum_{i=1}^{n} \sum_{j=1}^{n} \mathrm{w}_{\mathrm{ij}}\left(\mathrm{y}_{i}-\overline{\mathrm{y}}\right)\left(\mathrm{y}_{\mathrm{j}}-\overline{\mathrm{y}}\right)}{\mathrm{S}^{2} \sum_{i=1}^{n} \sum_{j=1}^{n} \mathrm{w}_{i j}}
$$

Where, $y_{i}$ is the required value for the region $i, \mathrm{n}$ is the total number of regions, and $W_{i j}$ represents the weight matrix of space. The expected value and variance of Moran'sI are formula (4) and formula (5) respectively:

$$
\begin{aligned}
& \mathrm{E}_{\mathrm{n}}\left(\text { Moran' }^{\prime} I\right)=\frac{1}{n-1} \\
& \operatorname{VAR}_{\mathrm{n}}\left(\text { Moran' }^{\prime} I\right)=\frac{\mathrm{n}^{2} w_{1}+n w_{2}+3 w_{0}^{2}}{w_{0}^{2}}-E_{\mathrm{n}}^{2}(\text { Moran's } I)
\end{aligned}
$$

The $\mathrm{Z}$ value of Moran'sI is calculated as follows formula (6) :

$$
\mathbf{Z}(\text { Moran'sI })=\frac{\text { Moran'sI - E } \text { E }_{n}(\text { Moran's } I)}{\sqrt{\operatorname{VAR}_{n}(\text { Moran's })}}
$$

Where, the Local indicator of spatial association (LISA) is used to measure the degree of spatial aggregation among the energy intensity of cities. The calculation formula of local Moran'sI index is as follows formula (7):

$$
\boldsymbol{I}_{\boldsymbol{i}}=\frac{\left(\mathrm{y}_{\mathrm{i}}-\overline{\mathrm{y}}\right)}{\mathrm{S}^{2}} \sum_{\mathrm{j}=1}^{\mathrm{n}} \mathrm{w}_{\mathrm{ij}}\left(\mathrm{y}_{\mathrm{i}}-\overline{\mathrm{y}}\right)
$$

In formula (7), $I_{i}$ is the local Moran's I index of the city $i$, and the meanings of other variables are consistent with those of the global Moran's I index formula. If $I_{i}>0$, it indicates that the high value is surrounded by the high value (" high-high "), or the low value is surrounded by the low value (" low-low ") 0 ; If $I_{i}<0$, it indicates the high value is surrounded by the low value (" high-low "), or the low value is surrounded by the high value (" low-high "). Software can be used to draw a Moran'sI scatter plot. The scatter plot has four quadrants corresponding to the four scenarios above.

The spatial econometric analysis model is as follows formula $(8)$ :

$$
\mathrm{LnCO}_{2 \mathrm{it}}=\alpha_{\mathrm{i}}+\beta_{\mathrm{k}} \operatorname{Ln} X_{\mathrm{k}}+\rho\left(\mathrm{I}_{\mathrm{T}} \otimes \mathrm{W}_{\mathrm{N}}\right) \mathrm{LnCO}_{2}+\theta_{\mathrm{k}}\left(\mathrm{I}_{\mathrm{T}} \otimes \mathrm{W}_{\mathrm{N}}\right) \operatorname{LnX}_{\mathrm{k}}+\varepsilon_{\mathrm{it}}
$$

$\beta_{k}$ is the coefficient of all independent variables (including control variables) in the spatial econometric analysis, $\rho$ refers to the endogenous space coefficient of the dependent variable (per capita carbon dioxide emissions), $W$ is the space weight matrix, $\theta$ is the exogenous space interaction coefficient of the dependent variable, $\mu$ and $\gamma$ are the specific effects of space and time; $X_{k}$ is the explanatory variable, namely the influencing factor.

The geographically weighted regression model is as follows formula (9) :

$$
\boldsymbol{Y}_{\mathrm{i}}=\alpha_{0}\left(U_{\mathrm{i}}, V_{\mathrm{i}}\right)+\sum_{\mathrm{k}-1}^{\mathrm{p}} \alpha_{\mathrm{k}}\left(U_{\mathrm{i}}, \quad V_{\mathrm{i}}\right) \mathrm{x}_{\mathrm{ik}}+\varepsilon_{\mathrm{i}}
$$

Where, $\left(\boldsymbol{U}_{\boldsymbol{i}}, \boldsymbol{V}_{i}\right)$ is the spatial coordinates of the sample point $\boldsymbol{i} ; \boldsymbol{\alpha}_{k}\left(\boldsymbol{U}_{k}, \boldsymbol{V}_{k}\right)$ is the value of continuous function $\boldsymbol{\alpha}_{k}(\boldsymbol{U}, \boldsymbol{V})$ at the point $\boldsymbol{i}$. If $\boldsymbol{\alpha}_{k}(\boldsymbol{U}, \boldsymbol{V})$ remains unchanged in space, the model becomes a global model.

\section{Result Analysis and Discussion}

\subsection{Aggregation Analysis and Discussion}

In this study, Moran'sI is used to detect the aggregation characteristics per capita carbon emissions from in Guangdong province. In order to examine the spatial dependence of carbon emissions in Guangdong province, the study tests the Moran'sI of carbon emissions. The results are shown in Table 2 below.

From the test results shown in Table 2 and Figure 1, it can be seen that the Moran'sI of per capita carbon emissions fluctuates between 0.65 and 0.7 in Guangdong province, which shows that there is a significant positive spatial correlation in per capita carbon emissions in Guangdong. According to Moran'sI overall trend chart, the Moran'sI of 
carbon emissions per capita has showed a downward trend in the past 10 years. Compared with the global Moran'sI in 2006 and 2015, the Moran'sI decreased from 0.7113 in 2006 to 0.6562 in 2015 . Overall, the Moran'sI test value shows a slow downward trend, which may be due to the effect of the "double transfer" policy in Guangdong. Labor-based and energy-dependent industries with high carbon emissions have began to transfer to Northern Guangdong and Western Guangdong, and the degree of its aggregation gradually weakened. Although the overall trend is weakening, the aggregation trend in 2015 is still significant.

Global Moran'sI shows that per capita carbon emissions have a strong spatial dependence, showing a strong spatial aggregation trend, but it has not been clear about the specific cluster scope. Because the Global Moran'sI is an overall indicator, its results only show the degree of aggregation of specific indicators within the region, but it can not detect the specific situation of aggregation in different spatial locations. Local Moran'sI is just the complementary form of Global Moran'sI. Through the local Moran'sI test, it is more clearly to see the agglomeration of different units in space. In order to show the local distribution better, LISA chart is used to visually show the spatial correlation characteristics of per capita carbon emissions, which makes the analysis results more detailed and in-depth. Figure 2 shows the aggregation characteristics and significance levels of per capita carbon emissions in 2006, 2010 and 2015, respectively.

From the local LISA chart and significance chart of per capita carbon emissions shown in Figure 2. the per capita carbon emissions of 21 prefecture-level cities in Guangdong province have a high spatial autocorrelation. The High-High (H-H) cluster of per capita gross carbon emissions is mainly distributed in the Pearl River Delta region, while the LowLow (L-L) cluster is mainly distributed in the eastern Guangdong region. This is mainly because the Pearl River Delta region has always been the core economic growth pole of Guangdong province. Rapid economic development and population aggregation are the main reasons for the Pearl River Delta region being in High-High $(\mathrm{H}-\mathrm{H})$ cluster from 2006 to 2015. And, the Low-Low L-L aggregation in Eastern Guangdong is closely related to its slower economic development. From the time axis, the specific cluster scope has a certain shrinking and expanding trend in 2006-2015, the High-High $(\mathrm{H}-\mathrm{H})$ cluster scope has decreased, and the Low-Low (L-L) cluster scope has a certain strengthening and expanding trend. Dongguan and Foshan withdrew from High-High $(\mathrm{H}-\mathrm{H})$ cluster in turn because of the policy impact and their high investment in the field of environmental protection, as described above. From 2010 to
2015, the High-High (H-H) cluster continued to shrink, while the Low-Low (L-L) cluster did not change, that is, the overall High-High $(\mathrm{H}-\mathrm{H})$ aggregation tended to weaken, which is consistent with the Global Moran'sI downward trend described. The study uses global and local Moran'sI to analyze the per capita carbon emissions of 21 cities in Guangdong province. It can be seen that the spatial econometric method is more realistic.

Moran'sI spatial correlation test has quantitatively proved the spatial dependence of carbon emissions in 21 cities of Guangdong province, that is, the carbon emissions in one region will have a certain inhibition or promotion effect on the carbon emissions in the adjacent regions. In order to further study which factors affect carbon emissions in space, the spatial econometric model is conducted. The results of Wald spatial lag, Wald spatial error, LR spatial lag and LR spatial error test show that the original hypothesis is rejected, so the Spatial Durbin Model is applicable. Moreover, this model does not impose any restrictions on the scale of potential spatial spillover effects (Elhorst, 2010)[33], which makes the model and its estimation of spillover effects more general. The test value of Hausman test is 59.2337, which significantly rejects the original hypothesis at $1 \%$ significance level. Finally, the SDM model with fixed spatial and temporal effects is selected as the final estimation model. Table 3 is the result of model regression. The difference between the second column and the third column is the estimation of error correction based on Lee and $\mathrm{Yu}(2010)$ [34-35].

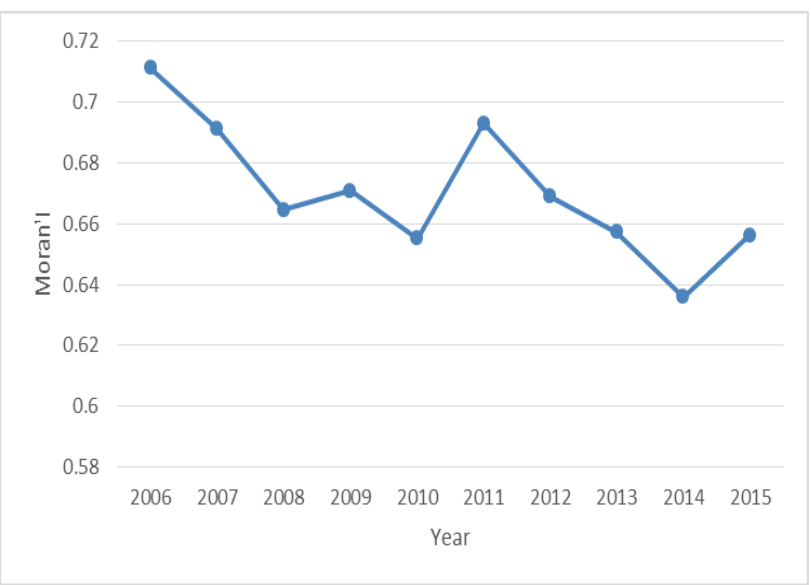

Fig. 1. Trend chart of overall Moran'sI of per capita carbon emissions, 2006-2015

Table 2. Overall Moran'sI of per capita carbon emissions,2006-2015

\begin{tabular}{c|c|c|c|c|c}
\hline Year & Morans'I & E(I) & VAR(I) & Z \\
2006 & 0.7113 & -0.05 & 0.0170 & 5.8358 & 5.6677 \\
2007 & 0.6913 & -0.05 & 0.0171 & 5.4582 & 5.000 \\
2008 & 0.6646 & -0.05 & 0.0171 & 0.000 & 0.000 \\
2010 & 0.6710 & -0.05 & 0.0172 & 0.000 \\
2011 & 0.6553 & -0.05 & 0.0173 & 5.6434 \\
2012 & 0.6931 & -0.05 & 0.0173 & 5.4630 \\
2013 & 0.6691 & -0.05 & 0.0173 & 5.3829 \\
2014 & 0.6574 & -0.05 & 0.0173 & 0.000 \\
2015 & 0.6359 & -0.05 & 0.0172 & 5.2215 \\
\end{tabular}




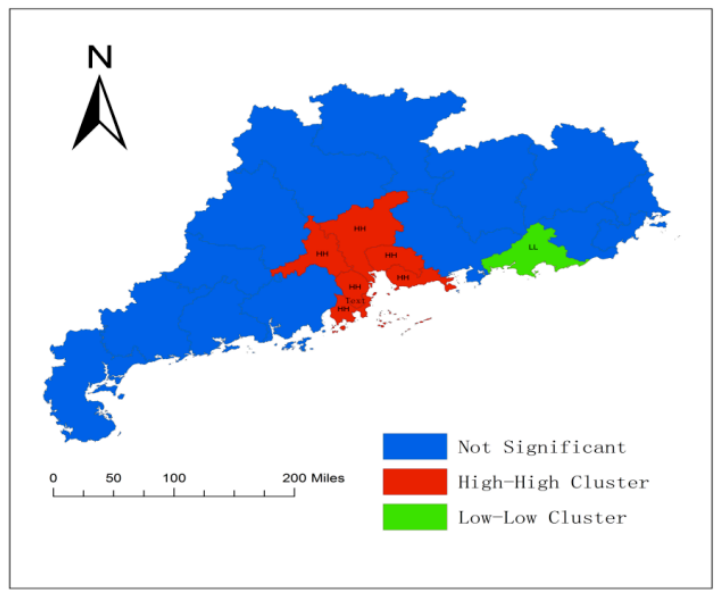

(a) 2006

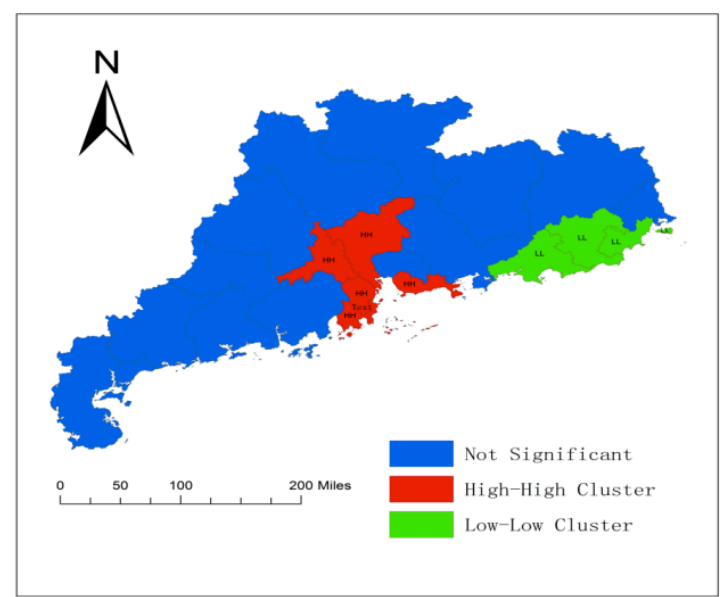

(b) 2010

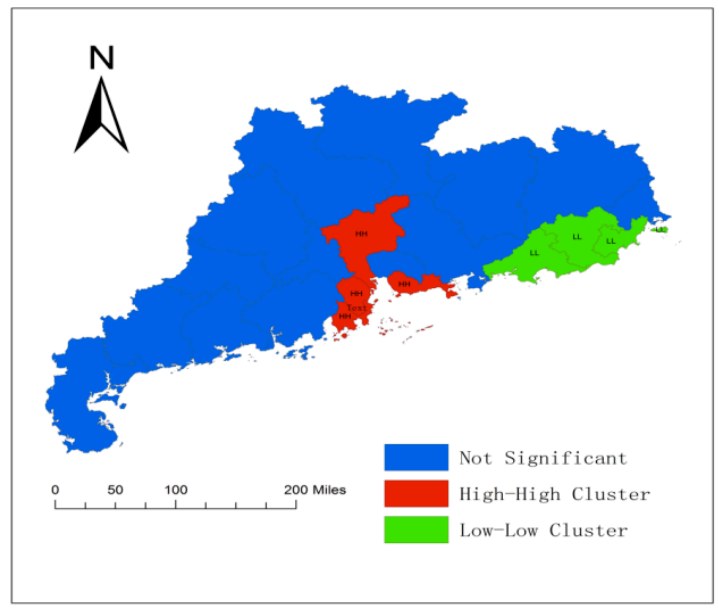

(c) 2015

Fig. 2. This is a figure, Schemes follow the same formatting. If there are multiple panels, they should be listed as: (a)LISA chart of per capita carbon emissions in Guangdong province, 2006;(b)LISA chart of per capita carbon emissions in Guangdong province, 2010;(c) LISA chart of per capita carbon emissions in Guangdong province, 2015

Table 3. Regression results of spatial panel model under fixed spatial and temporal effects

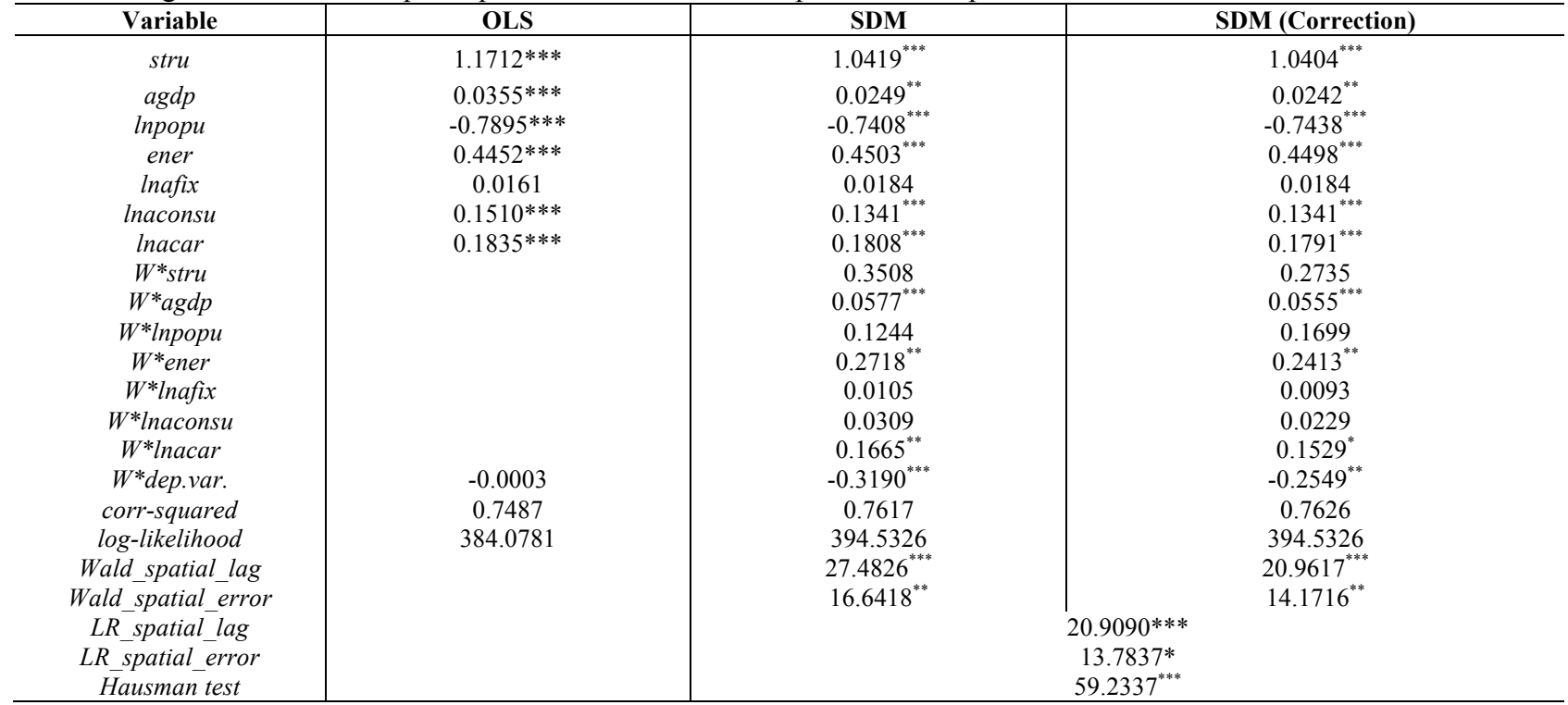

Note: *, **, and $* * *$ indicate statistical significance at $10 \%, 5 \%$, and $1 \%$

In the model, stru, agdp、Inpopu、ener, Inafix, Inaconsu and lnacar respectively indicates the impact of the influencing factors on the per capita carbon emissions in the region, including industrial structure, economic development, population size, energy intensity, per capita fixed asset investment, per capita gross retail sales and per capita 
private car ownership. $W^{*}$ stru $、 W^{*}$ agdp、W*Inpopu 、 $W^{*}$ ener 、 $W^{*}$ Inafix 、 $W^{*}$ Inaconsu and $W^{*}$ Inacar respectively indicate the influence of each factor on per capita carbon emissions in the adjacent regions. $\boldsymbol{W}^{*}$ dep.var. is the autoregressive coefficient of per capita energy carbon emissions. The modified corr-squared of the model is 0.7626 and the maximum likelihood is 394.5326 . As shown in Table 3, by comparing the spatial and temporal fixedeffect model with the spatial and temporal fixed-effect SDM model, we can clearly see that the general model overestimates the impact of its influencing factors on per capita carbon emissions, because the non-SDM model does not take into account that the changes of influencing factors in other regions also have a certain impact on local carbon emissions.

From the estimation results of the error correction estimates of SDM model with fixed spatial and temporal effects, we can see that the direct effect coefficient of industrial structure on per capita carbon emissions is positive 1.0404 , which passes the significance test at $1 \%$ level. The effect of industrial structure changes in adjacent regions on per capita carbon emissions is not significant. This means that the per capita carbon emissions of the region can increase by 1.0404 units for each increased unit of industrial structure of the region (the ratio of secondary industry output value to gross output value). From the absolute values of each coefficient, we can see that the impact of the added value of secondary industry, which has considered spatial effects on carbon emissions, is the greatest.

The direct effect coefficient of per capita GDP on per capita carbon emissions is positive 0.0242, and the effect coefficient of per capita GDP in adjacent regions on per capita carbon emissions of this region is also positive 0.0555 , which has passed the significant test at the level of 5\% and $1 \%$ respectively. This means that for every increased unit of GDP per capita, the per capita carbon emissions in the region can increase by 0.0242 units, and for every increased unit of GDP per capita in the adjacent regions, the per capita carbon emissions in the region can also increase by 0.0555 units. The impact of the increase of per capita GDP in adjacent regions on per capita carbon emissions in this region is mainly due to the close economic distance between the two regions and a certain spatial economic correlation.

The direct effect coefficient of urban resident population on per capita carbon emissions is negative 0.7438 , which passes the significance test at the level of $1 \%$. The spillover effect of population change in the adjacent regions is not significant, but the increase of population in this region reduces the per capita carbon emissions. This may be due to the fact that the population growth rate of Guangdong province is faster than the increase rate of carbon emissions. On the other hand, it also reflects that the population growth is not the main source of the increase of carbon emissions in Guangdong province.

Energy intensity is the ratio of energy consumption to GDP, which reflects the increase of energy consumption per increased unit of GDP. The direct effect coefficient of energy intensity on per capita carbon emissions is positive 0.4498 , which passes the significance test at the level of $1 \%$, which shows that per unit increase of energy intensity in this region can increase per capita carbon emissions by 0.4498 units. The energy intensity of the adjacent regions also has a spillover effect on the per capita carbon emissions carbon emissions in this region. For each increased unit of energy intensity in the adjacent regions, the per capita carbon emissions of this region can be increased by 0.2718 units, which passes the $5 \%$ significance test. It may be caused by spillover effect by the improvement of energy efficiency in the adjacent regions.

\subsection{Heterogeneity Analysis and Discussion}

Ordinary OLS estimation is only an estimation of explained variables by explaining variables from the whole level, ignoring the influence of spatial location. Geographically weighted regression model (GWR) considers the influence of geographical location distance on the relationship between independent variables and dependent variables. The regression coefficients change with the change of geographical location, which makes the regression results more credible. At present, the regression of GWR can only deal with cross-sectional data. In order to make the results more general, this study carries out GWR regression on the mean value of the data from 2006 to 2015 , so as to reflect the general effect of spatial mechanism of carbon emissions influencing factors. In this study, the natural break point method is used to visualize it in Geographic Information System (GIS).

Because of production, the carbon emissions of tertiary industries are the largest. The industrial structure refers to the proportion of the added value of the secondary industry in the gross national economic output. From Figure 3(a), we can see that the impact of industrial structure on carbon emissions is very different in space. The regions with greater impact of industrial structure on carbon emissions are mainly located in Western and Eastern Guangdong. The region with the strongest impact of industrial structure on carbon emissions is Zhanjiang in the west, followed by Maoming, Yangjiang, Yunfu and Meizhou and Chaozhou in eastern Guangdong. The regions with the weakest impact is in the central region, such as Guangzhou, Shenzhen and Dongguan. This shows that the closer to the eastern and western sides of Guangdong, the more developed the secondary industry in the region can be, so that even with the slight changes in the secondary industry in the industrial structure, the per capita carbon emissions will be significantly reduced. Therefore, these regions need to focus on upgrading the industry and reducing the proportion of the secondary industry.

Per capita GDP represents the level of economic development in a region. From Figure 3(b), we can see that there are significant spatial differences in the impact of economic growth on carbon emissions. The impact of economic growth on carbon emissions is gradually increasing from western Guangdong to Eastern Guangdong. Chaozhou, Shantou and Jieyang are the regions where economic growth has the strongest impact on carbon emissions, followed by Jiangmen, Zhongshan and Foshan, and Zhanjiang and Maoming in Western Guangdong are the regions where economic growth has the weakest impact on carbon emissions. The regression coefficients of per capita GDP are continuously distributed from west to East in space, which indicates that the regression coefficients of per capita GDP are also in the trend of aggregation in space. The level of economic development is one of the important factors affecting per capita carbon emissions. In terms of economic development, the impact of Eastern Guangdong on per capita carbon emissions is significantly higher than that of Western Guangdong, which indicates that Eastern Guangdong needs to optimize its economic development mode. We should change the way of energy-driven economic growth in the past and move towards the direction and mode of low-carbon green sustainable development. 


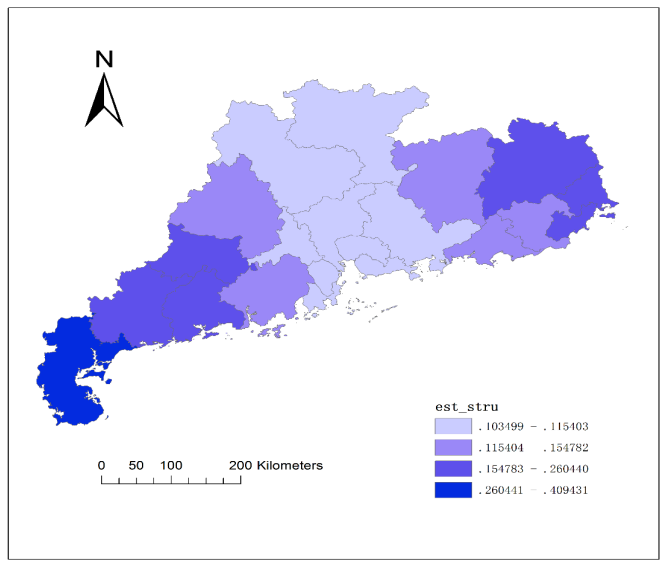

(a) Spatial distribution of regression coefficient of industrial structure

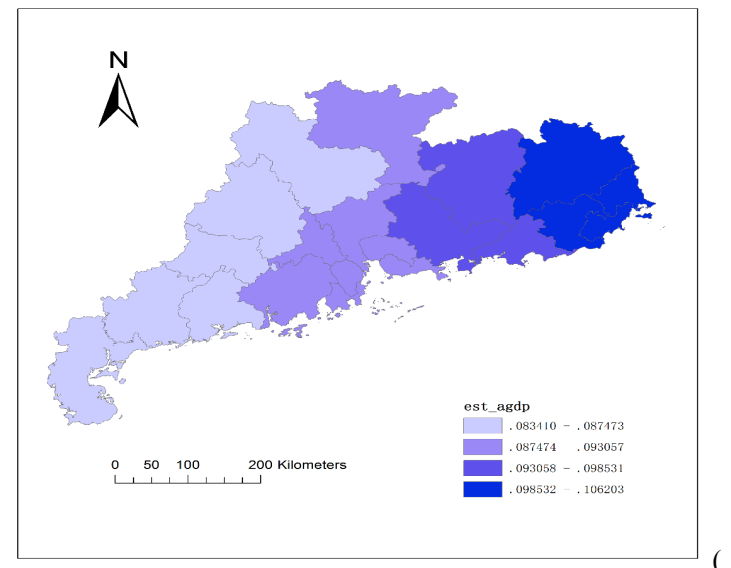

b) Spatial distribution of the regression coefficient of living standard

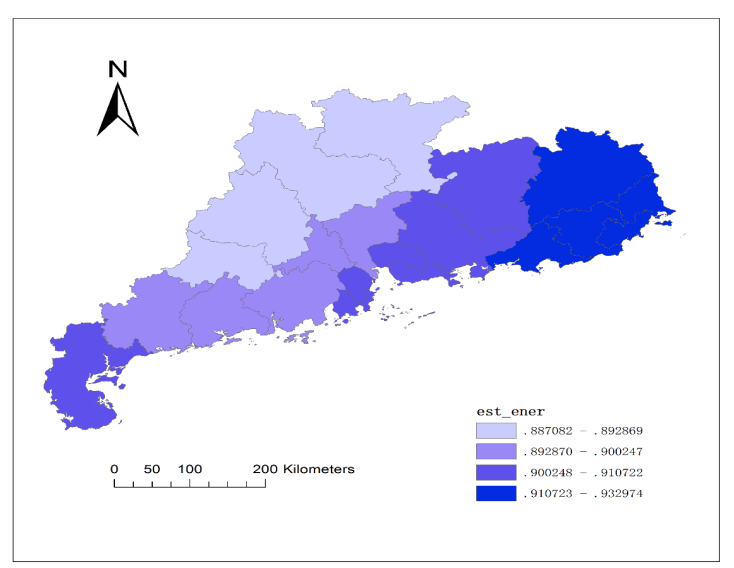

(c)Spatial distribution of regression coefficient of energy consumption intensity

Fig. 3. This is a figure, Schemes follow the same formatting. If there are multiple panels, they should be listed as: (a);(b);(c)

Energy consumption intensity refers to the ratio of GDP to carbon emissions. From Figure 3(c), we can see that there are significant spatial differences in the impact of energy consumption intensity on carbon emissions. The impact of energy consumption intensity on carbon emissions generally shows a trend of being strong at both sides, weak in the middle, especially in Northern Guangdong. The regions with the strongest impact on carbon emissions are Zhanjiang, Maoming, Chaozhou, Shantou and Jieyang, while the regions with the weakest impact are Shaoguan, Qingyuan and Zhaoqing in Northern Guangdong. The intensity of energy consumption in eastern Guangdong has the greatest impact on per capita carbon emissions, which indicates that the intensity of carbon emissions plays an important role in carbon emission reduction. In order to achieve better carbon emission reduction, we should make efforts to reduce carbon emissions per unit of GDP. Eastern Guangdong should pay attention to the improvement of energy efficiency. We can improve the energy efficiency by upgrading the technology level and researching the cutting-edge low-carbon emission reduction technology. At the same time, we should also pay attention to the development of new energy and encourage local enterprises and residents to use new energy.

\section{Conclusions}

In order to explore the spatial aggregation and heterogeneity of carbon dioxide emissions and reveal the relationship between carbon dioxide and influencing factors, the spatial econometric and the geographically weighted regression models were developed to analyze the spatial aggregation and heterogeneity of the panel data of a China's low-carbon pilot province and its cities from 2006 to 2015. The following conclusions could be drawn:

(1) Carbon dioxide emissions have a strong spatial correlation, and show remarkable aggregation, thereby forming different types of clusters.

(2) Several developed regions such as the Pearl River Delta, are mainly H-H clusters, whereas other regions, such as eastern Guangdong are considered $\mathrm{L}-\mathrm{L}$ clusters.

(3)The added value of the secondary industry has a greater impact on the carbon dioxide emissions. The changes of per capita GDP, energy intensity, and per capita private car ownership in adjacent regions also have a certain impact on per capita carbon emissions in the region, with a certain spatial spillover effect.

(4)The spatial heterogeneity of the influencing factors of carbon dioxide emission is significant.

This study combines the analysis of experimental data with the study of spatial econometric theory, and proposes a new direction in the emission reduction of carbon dioxide. The established spatial econometric model and geographically weighted regression model are more consistent with the reality, which is significant to the policy formulation on the emissions reduction of regional carbon dioxide. However, this study lacks existing air quality data. Therefore, in future studies, air quality data should be 
combined with other studies, so as to achieve a more comprehensive understanding of the action mechanism and rules of carbon dioxide emissions.

\section{Acknowledgements}

This work was supported by the Development and Reform Commission of Shenzhen City (Grant Nos. [2017]1089 and [2018]725).
This is an Open Access article distributed under the terms of the Creative Commons Attribution License

\section{References}

1. Sirag, A., Matemilola, B. T., Law, S. H., et al., "Does environmental Kuznets curve hypothesis exist? Evidence from dynamic panel threshold". Journal of environmental economics and policy, 7(2), 2018, pp.145-165.

2. Atasoy, B. S., "Testing the environmental Kuznets curve hypothesis across the US: Evidence from panel mean group estimators". Renewable and Sustainable Energy Reviews, 77, 2017, pp.9901000.

3. Fisher-Vanden, K., Jefferson, G. H., Liu, H., et al., "What is driving China's decline in energy intensity?". Resource and Energy economics, 26(1), 2004, pp.77-97.

4. He, J. K., "Analysis of CO2 Emissions Peak: China's Objective and Strategy".China Population Resources and Environment, 23 (12), 2013, pp.1-9

5. Fang, D. B., Dong, W., Yu, Q., “Optimization of China's Energy Consumption Structure under Trend of Low-carbon Transition". Technology Economics, 35(7), 2016, pp.71-79

6. Li, J., Wang, Y., Wang, Y., "Analysis of Decoupling Trend of Carbon Emissions and Carbon Emission Reduction Potential in Tianjin: Based on Panel Data from 2007 to 2016". Ecological Economy, (04), 2019, pp.26-32.

7. Qiu, L. X., Xu, H. T., "Prediction of Carbon Emission Trend in Chinese Typical Cities under Benchmark and Disturbance Situations". Urban Problems, (03), 2019, pp.12-22.

8. Chen, L., Wan, P. B., "Emission Reduction Effects of Kyoto Protocol and its Clean Development Mechanism: Based on Data Analysis of China's Participation in Global Environmental Governance Micro-projects". Economic Research Journal, (03), 2019, pp.55-71

9. Hulten, C. R., “Divisia Index Numbers”. Econometrica, 41(6), 1973, pp.1017-1025.

10. Boyd, G., "Separating the Changing Composition of US Manufacturing Production from Energy Efficiency Improvements: A Divisia Index Approach". Energy, 8(2), 1987, pp.77-96.

11. Ang, B. W., Liu, F. L., "A New Energy Decomposition Method: Perfect Decomposition and Consistent in Aggregation". Energy, 26(6), 2001, pp.537-548.

12. Emmanouil, H., Heracles, P., Dias, H., "CO2 Emissions in Greece for 1990-2002: A Decomposition Analysis and Comparison of Results Using the Arithmetic Mean Divisia Index and Logarithmic Mean Divisia Index Techniques". Energy, 33, 2008, pp.492-499.

13. Mei, L. H., Yang, H., "Grey Relational Analysis of Carbon Emission Factors in China Based on Kaya Formula". Journal of Yunnan University of Finance and Economics, (4), 2011, pp.66-70.

14. Chen, L., "Analysis of the Influencing Factors of the Change of Energy Consumption Carbon Emissions in China-Based on Inputoutput Model". Sino-Global Energy, 18(1), 2013, pp.17-22.

15. Li, G. Z., Li, Z. Z., "Regional Differences and Influencing Factors of Carbon Dioxide Emissions in China". China Population, Resources and Environment, (5), 2010, pp.22-27.

16. Li, Y., Zhang, C. P., Xie, X. H., "Analysis of the Differences and Influencing Factors of Carbon Dioxide Emissions in China Empirical Analysis Based on Industrial Sub-sector". Journal of Industrial Technological Economics, 31(8), 2012, pp.39-45.

17. Zhao, X., Long, R. Y., "An Empirical Analysis of Carbon Emissions and Factor Decomposition in Jiangsu Province". China Population, Resources and Environment, 20(7), 2010, pp.25-30.

18. Wang, P., Zhang, R. H., "Analysis of the Correlation Between the Growth of Construction Land and the Change of Carbon Emissions in Shaanxi Province". Environmental Protection Science, 40(2), 2014, pp.82-85.
19. Shen, Z. Q., Tang, D. C., Zhong, F. X., Li, C. S., Jiang, Y., "Factor Decomposition Model and Empirical Analysis of Carbon Emission in Wuxi City". Environmental Protection Science, 40(1), 2014, pp.6-10.

20. Heil, M., Wodon, Q., "Inequality in $\mathrm{CO} 2$ Emissions between Poor and Rich Countries". The Journal of Environmental and Development, 6(4),1997, pp.426-452.

21. Padilla, E., Serrano, A., "Inequality in $\mathrm{CO} 2$ Emissions across Countries and Its Relationship with Income Inequality: A Distributive Approach". Energy Policy, 34(14), 2006, pp.17621772 .

22. Duro, J. A., Padilla, E., "International Inequalities in Per Capita CO2 Emissions: A Decomposition Methodology by Kaya Factors". Energy Economics, 28(2), 2006, pp.170-187.

23. Cantore, N., Padilla, E., "Equality and $\mathrm{CO} 2$ Emissions Distribution in Climate Change Integrated Assessment Modelling". Energy, 35(1), 2010, pp.298-313.

24. Clarke-Sather, A., Qu, J., Qin, W., et al., "Carbon Inequality at the Subnational Scale: A Case Study of Provincial-level Inequality in CO2 Emissions in China 1997-2007”. Energy Policy, 39(9), 2011, pp.5420-5428.

25. Zhang, Y., Zhang, J., et al., "Regional Differences in the Factors that Influence China's Energy-related Carbon Emissions, and Potential Mitigation Strategies". Energy Policy, 39(12), 2011, pp.7712-7718.

26. Meng, L., Guo, J., Chai, J., et al., "China's Regional CO2 Emissions: Characteristics, Inter-regional Transfer and Emission Reduction Policies". Energy Policy, 39(10), 2011, pp.6136-6144.

27. Lin, B. Q., Huang, G. X., "Evolution Trend of Regional Carbon Emissions in China under Gradient Development Model I - Based on Spatial Analysis”. Journal of Financial Research, (12), 2011, pp.35-46.

28. Yang, Q., Liu, H. J., "Decomposition and Influencing Factors of Regional Differences in Carbon Dioxide Emissions in China Based on Interprovincial Panel Data 1995-2009". The Journal of Quantitative \& Technical Economics, (5), 2012, pp.36-49.

29. Xiao, F., Hu, Z. H., Wang, K. X., et al., "Spatial Distribution of Energy Consumption and Carbon Emission of Regional Logistics". Sustainability, 7(7), 2015, pp.9140-9159.

30. Song, D. Y., Yi, Y. C., "Foreign Direct Investment and China's Carbon Emissions". China Population, Resources and Environment, 21(1), 2011, pp.49-52.

31. Li, J. B., Huang, X. J., Wu, C. Y., Zhou, Y., Xu, G. L., "Spatial Heterogeneity Analysis of Influencing Factors of Carbon Emissions in Provinces of China". Economic Geography, (11), 2015, pp.2128.

32. Moran, P. A., "Test for the Serial Dependence of Residuals". Biom etrika, (37), 1950, pp.178-181.

33. Elhorst, J. P., "Spatial panel data models. In: Fischer MM, Getis A (eds) Handbook of applied spatial analysis: software tools, methods and applications". Springer Berlin, 2010, pp 377-407.

34 Lee, L. F., J, Yu., "Estimation of spatial autoregressive panel data models with fixed effects". Journal of Econometrics, 154, 2010, pp.165-185.

35. Lee, L. F., J, Yu., "Some recent developments in spatial panel data models". Regional Science and Urban Economics, 40(5), 2010, pp.255-271. 